\title{
Intermolecular Interactions in Binary Mixture of Polymethylmethacrylate
}

\author{
RICHA SAXENA $^{* 1}$ and S. C. BHATT ${ }^{2}$ \\ ${ }^{1}$ IFTM University, Lodhipur, Rajput, Moradabad-244001, (Uttar Pradesh) India \\ ${ }^{2}$ Ultrasonic and Dielectric Laboratory, Department of Physics, H.N.B. Garhwal University, \\ Srinagar-246174, Garhwal, (Uttarakhand) India \\ saxena.richa23@gmail
}

Received 2 July 2018 / Accepted 3 August 2018

\begin{abstract}
Experimental values of density, viscosity and ultrasonic velocity of binary mixtures of polymethylmethacrylate with acetic acid studies have been carried out over entire concentration range $0.3 \%$ to $1.0 \%$ at $55^{\circ} \mathrm{C}$ temperature are reported. The measurements were carried out at $1 \mathrm{MHz}$ frequency. From these different acoustical parameters adiabatic compressibility, acoustic impedance and intermolecular free length have been calculated by using measured values of ultrasonic speed, density and viscosity. The solute and solvent interactions are discussed.
\end{abstract}

Keywords: Ultrasonic velocity, Adiabatic compressibility, Acoustic impedance and intermolecular free length

\section{Introduction}

Ultrasonic $^{1,2}$ volumetric $^{3}$ and viscometric ${ }^{4,5}$ properties of binary liquid mixtures have been investigated by a number of researchers over the past several years. The extensive use of polymeric materials in technology has necessitated investigations of the molecular investigations of the molecular interactions of polymers and solvents ${ }^{6-10}$. The ultrasonic technique is powerful and effective tool for investigation of polymer solutions and behavior of polymer chain in an ultrasonic field. In chemical industry, knowledge of the thermodynamic properties of non-electrolyte solutions is essential in the design involving chemical separation, heat transfer, mass transfer and fluid flow. The ultrasonic investigation finds extensive application in the characterizing aspects of the physiochemical behavior of liquid mixtures. Mixed solvents, rather than pure solvents find practical applications in most chemical processes, their properties are less known ${ }^{11-12}$. Derived parameters from ultrasonic speed measurement and the corresponding excess functions provide qualitative information regarding the nature and strength of interactions in liquid mixtures.

Ultrasonic waves can propagate through matter and therefore they can be used for detecting the discontinuities present in cast or forged materials ${ }^{13}$. The extensive uses of polymeric materials in technology have prompted ultrasonic studies to help to understand the structures of polymers and molecular interactions in solutions that provide knowledge on the solvophilic or solvophobic nature of polymers ${ }^{14-17}$. 


\section{Experimental}

In the present investigation liquid solution of polymethylmethacrylate (of molecular weight $\approx 15,000$ in solid form) with acetic acid is used. The solutions were prepared by adding known weight of polymethylmethacrylate to fixed volume of acetic acid and stirring under reflex, until a clear solution was obtained. The concentration range studied in the solution is $0.3 \%-1.0 \%$ (v/v). Different acoustical parameters like adiabatic compressibility, acoustic impedance and intermolecular free length were calculated at different concentration like $1.0 \%, 0.8 \%, 0.6 \%, 0.5 \%, 0.4 \%$ and $0.3 \%$ and at $55^{\circ} \mathrm{C}$ temperature at $1 \mathrm{MHz}$. The ultrasonic speeds were measured by using variable path ultrasonic interferometer with reproducibility of $\pm 0.4 \mathrm{~m} / \mathrm{s}$ at $35^{\circ} \mathrm{C}$. The temperature of the solution has been kept constant by circulating water from the thermostatically controlled $\left( \pm 0.1{ }^{\circ} \mathrm{C}\right)$ water bath. The densities at different temperature were measured using $10 \mathrm{~mL}$ specific gravity bottle and single pan microbalance. The uncertainty in density measurements was found to be about $0.5 \mathrm{~kg} / \mathrm{m}^{3}$. The viscosity of the mixtures was determined by using Ostwald's viscometer, which was kept inside a double walled jacket, in which water from thermostat water bath was circulated. Inner cylinder of this double-wall-glass jacket was filled with water of desired temperature so as to establish and maintain the thermal equilibrium. The accuracy in the viscosity measurements is within $\pm 0.5 \%$. These parameters are calculated by using standard relations ${ }^{18,19}$.

\section{Results and Discussion}

Densities, viscosities and ultrasonic velocities of polymethylmethacrylate are shown in Tables 1 to 3 and Figure 1 to Figure 3 respectively. Table 1 and Figure 1 represent the variation of density of polymethylmethacrylate with concentration at $55^{\circ} \mathrm{C}$ temperature. It is clear from Figure 1 that density increases with increase in concentration this behavior is in agreement with the results reported by other workers ${ }^{20}$. Table 2 and Figure 2 show that, viscosity increases with increase in concentration of polyvinyl alcohol in the solution. Present dependence is in accordance with the reported by other workers ${ }^{21}$. The variations of ultrasonic velocity with temperature and concentration have been shown in Table 3 and Figure 3. Ultrasonic velocity increases with increase in concentration of PMMA in the solution. It is evident from our investigation that our present results are in good agreement with the results reported by others workers ${ }^{22}$. Variation of adiabatic compressibility with concentration is shown in Table 4 and Figure 4. It is evident that adiabatic compressibility decreases with increase in concentration of polymethylmethacrylate in solution. Table 5 and Figure 5 depict the variation of acoustic impedance with concentration. It increases with increase in concentration of polymethylmethacrylate in the solution. Variation of intermolecular free length with concentration is presented in Table 6 and Figure 6 which shows that it decreases with increase in concentration of PMMA in solution.

Table 1. Density $\left(\times 10^{3} \mathrm{~kg} / \mathrm{m}^{3}\right)$ of polymethylmethacrylate (PMMA) with concentration at $55{ }^{\circ} \mathrm{C}$ temperature and at $1 \mathrm{MHz}$ frequency

\begin{tabular}{cc}
\hline Concentration, \% & Density, $\mathrm{kg} / \mathrm{m}^{3}$ \\
\hline 1.0 & 0.9999 \\
0.8 & 0.9996 \\
0.6 & 0.9994 \\
0.5 & 0.9992 \\
0.4 & 0.9991 \\
0.3 & 0.8926 \\
\hline
\end{tabular}




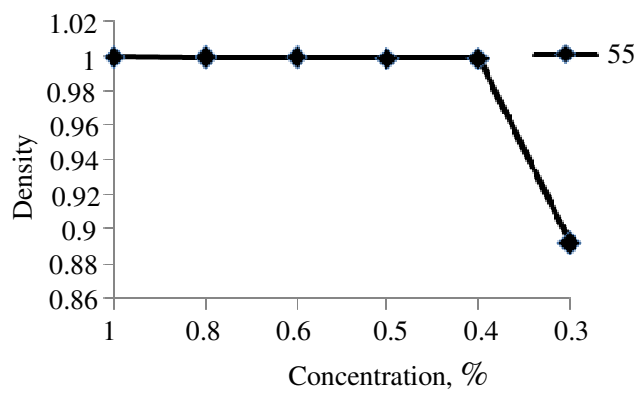

Figure 1. Variation of density with concentration at $55^{\circ} \mathrm{C}$

Table 2. Viscosity ( $\left.\times 10^{-1} \mathrm{~Pa} . \mathrm{s}\right)$ of polyvinyl alcohol (PVA) at different temperature and concentration at $1 \mathrm{MHz}$ frequency

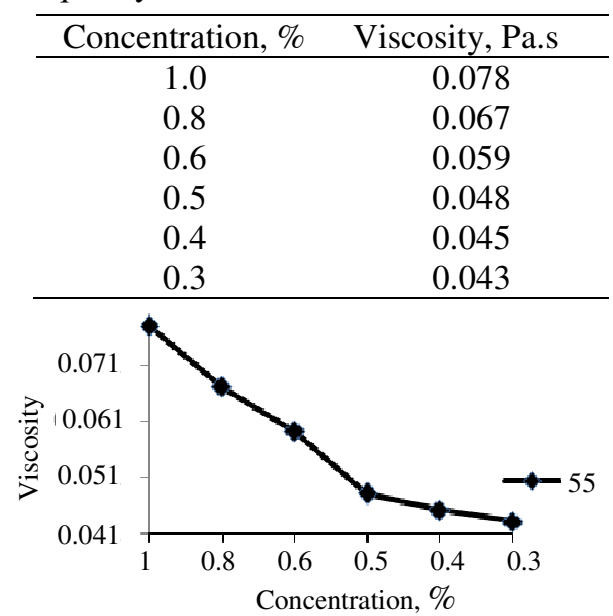

Figure 2. Variation of viscosity with concentration at $55^{\circ} \mathrm{C}$

Table 3. Ultrasonic velocity $(\mathrm{m} / \mathrm{s})$ of with concentration at $55^{\circ} \mathrm{C}$ temperature and at $1 \mathrm{MHz}$ for polymethylmethacrylate (PMMA)-

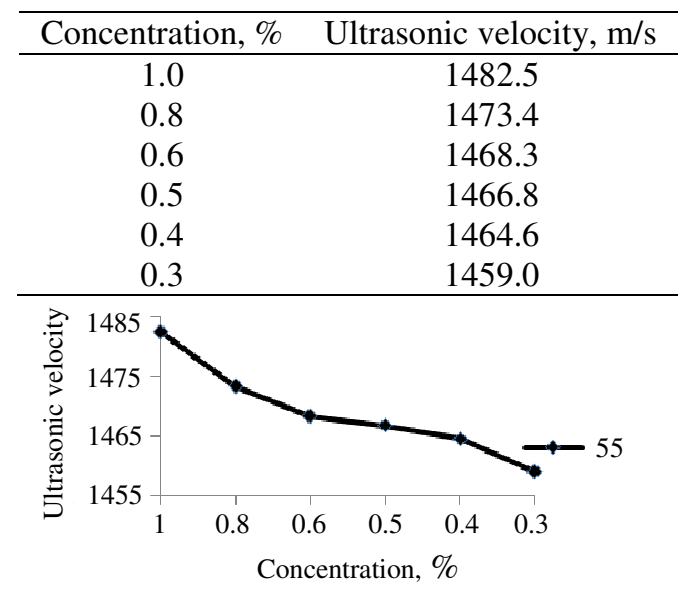

Figure 3. Variation of ultrasonic velocity with concentration at $55{ }^{\circ} \mathrm{C}$ 
Table 4. Adiabatic compressibility $\left(\times 10^{-10} \mathrm{~kg}^{-1} \mathrm{~ms}^{2}\right)$ with concentration at $55^{\circ} \mathrm{C}$ temperature and at $1 \mathrm{MHz}$ for polymethylmethacrylate (PMMA)-

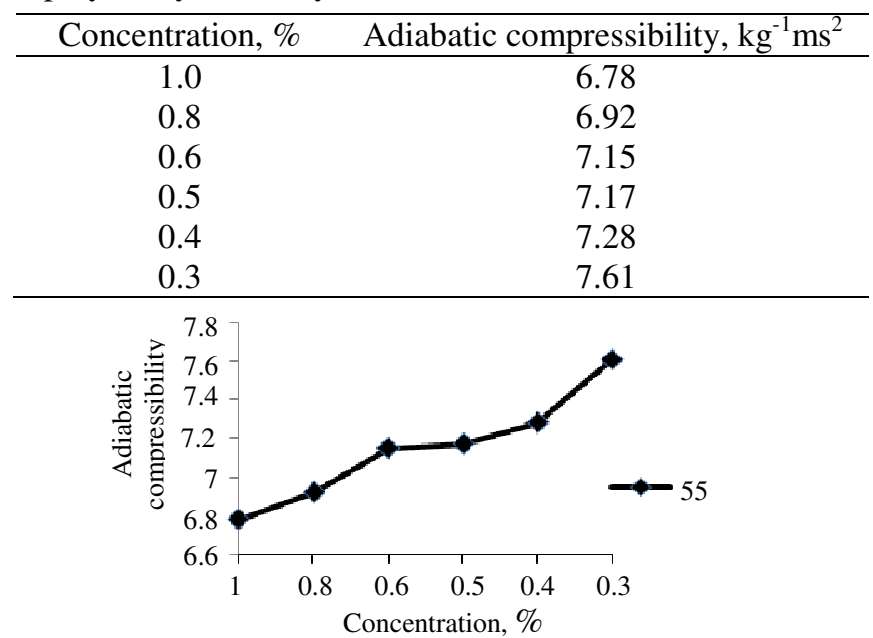

Figure 4. Variation of adiabatic compressibility with concentration at $55{ }^{\circ} \mathrm{C}$

Table 5. Acoustic impedance $\left(x 10^{3} \mathrm{kgm}^{2} \mathrm{~s}^{-1}\right)$ with concentration at $55^{\circ} \mathrm{C}$ temperature and at $1 \mathrm{MHz}$ for polymethylmethacrylate (PMMA)

\begin{tabular}{|c|c|}
\hline Concentration, $\%$ & Acoustic impedance, $\mathrm{kgm}^{2} \mathrm{~s}^{-1}$ \\
\hline 1.0 & 1220 \\
\hline 0.8 & 1194 \\
\hline 0.6 & 1189 \\
\hline 0.5 & 1186 \\
\hline 0.4 & 1170 \\
\hline 0.3 & 1165 \\
\hline \multirow[t]{2}{*}{ 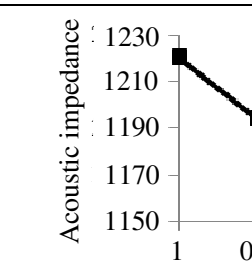 } & \\
\hline & $\begin{array}{llll}0.8 & 0.6 & 0.5 & 0.4\end{array}$ \\
\hline
\end{tabular}

Figure 5. Variation of acoustic impedance with concentration at $55^{\circ} \mathrm{C}$

Table 6. Intermolecular free length $\left(\times 10^{-13} \mathrm{~m}\right)$ at different temperature and concentration at $1 \mathrm{MHz}$ for polymethylmethacrylate (PMMA)-

\begin{tabular}{cc}
\hline Concentration, \% & Intermolecular free length, $\mathrm{m}$ \\
\hline 1.0 & 3.568 \\
0.8 & 3.575 \\
0.6 & 3.620 \\
0.5 & 3.625 \\
0.4 & 3.630 \\
0.3 & 3.758 \\
\hline
\end{tabular}




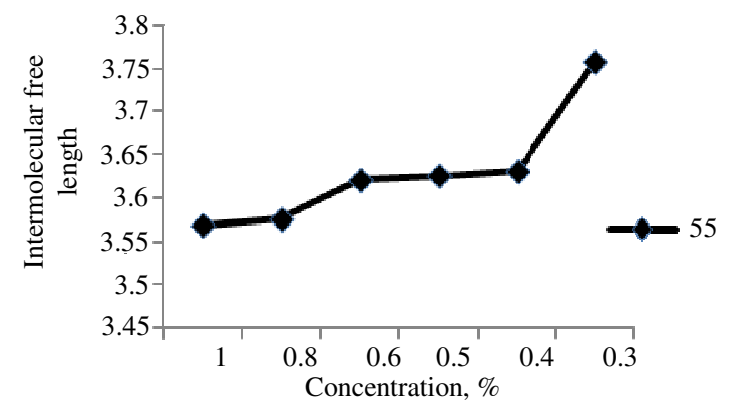

Figure 6. Variation of intermolecular free length with concentration at $55^{\circ} \mathrm{C}$

\section{References}

1. Ali A and Nabi F, J Disp Sc Tech., 2010, 31, 1326.

2. Rastogi R P, Nath J and Misra J, J Phys Chem., 1967, 71(5), 1277-1286; DOI: $10.1021 / \mathrm{j} 100864 \mathrm{a} 015$

3. Rathnam M V, Sayed R T, Bhanushali K R and Kumar M S S, J Mol Liq., 2012, 166, 9-16; DOI:10.1016/j.molliq.2011.10.020

4. Nabi F, Jesudason C G, Malik M A and Al Thabaiti S A, Chem Eng Comm., 2013, 200(1), 77-92; DOI:10.1080/00986445.2012.691920

5. Awasthi A and Awasthi A, Thermochim Acta, 2012, 537, 57-64; DOI:10.1016/j.tca.2012.03.001

6. Sannanigannavar, F M, Navati B S and Ayachit N H, Polymer Bulletin, 2013, 70(2), 603-618; DOI:10.1007/s00289-012-0881-0

7. $\quad$ Singh K P and Bhatt S C, Appl Phys Res., 2010, 2(1), 35-45.

8. Vasoya, P J, Mehta N M, Patel V A and Parsania P H, J Sci Ind Res., 2007, 66(10), 841-848.

9. Mehta S K, Jain R, Sharma S and Bhasin K K, J Mole Liqs., 2005, 122(1-3), 15-20; DOI:10.1016/j.molliq.2004.12.007

10. Kannappan V, Santhi B S and Jonathan D R, Indian J Chem A, 2014, 53(6), 688-694.

11. Gracia B, Alcalde R, Leal J M and Matos J S, J Chem Soc., Faraday Trans., 1997, 93, 1115-1518; DOI:10.1039/A607876A

12. Pitzer K S, Thermodynamics, $3^{\text {rd }}$ Ed. McGraw-Hill Book Co., NY, 1995.

13. Metals handbook, vol.2, ASM, 1976.

14. Saxena Richa and Bhatt S C, Rasayan J Chem., 2017, 10(4), 1340-1347.

15. Saxena Richa and Bhatt S C, Global J Sci Frontier Res., 2017, 17(4).

16. Saxena Richa and Bhatt S C, Adv Mat Sci Engg., 2018, Vol 2018, Article ID 1738612; DOI: $10.1155 / 2018 / 1738612$

17. Saxena Richa, Int J Sci Res., 2015, 4(9), 2075-2077

18. Saxena Richa and Bhatt S C, Int J Chem., 2010, 2, 164.

19. Marcue Y, Introduction to liquid State chemistry, (New York, Wiley Int.), 1977.

20. Saxena Richa, Int J Sci Res., 2014, 3.

21. Esquivel R S, Tan B, Abdelraziq I, Yun S S and Stumpf F B, J Acous Soc Am., 1993, 93(2), 819; DOI:10.1121/1.405444

22. Varadu Rajulu A and Reddy Lakshminarayana, J Acous Soc India., 1999, 27, 379. 